\title{
Seasonal variations and north-south asymmetries in polar wind outflow due to solar illumination
}

\author{
Lukas Maes $^{1}$, Romain Maggiolo ${ }^{1}$, and Johan De Keyser ${ }^{1,2}$ \\ ${ }^{1}$ Royal Belgian Institute for Space Aeronomy, Brussels, Belgium \\ ${ }^{2}$ KU Leuven Center for Mathematical Astrophysics, Celestijnenlaan 200B, 3001 Leuven, Belgium \\ Correspondence to: Lukas Maes (lukas.maes@aeronomie.be)
}

Received: 10 June 2016 - Revised: 17 October 2016 - Accepted: 19 October 2016 - Published: 7 November 2016

\begin{abstract}
The cold ions (energy less than several tens of electronvolts) flowing out from the polar ionosphere, called the polar wind, are an important source of plasma for the magnetosphere. The main source of energy driving the polar wind is solar illumination, which therefore has a large influence on the outflow. Observations have shown that solar illumination creates roughly two distinct regimes where the outflow from a sunlit ionosphere is higher than that from a dark one. The transition between both regimes is at a solar zenith angle larger than $90^{\circ}$. The rotation of the Earth and its orbit around the Sun causes the magnetic polar cap to move into and out of the sunlight. In this paper we use a simple set-up to study qualitatively the effects of these variations in solar illumination of the polar cap on the ion flux from the whole polar cap. We find that this flux exhibits diurnal and seasonal variations even when combining the flux from both hemispheres. In addition there are asymmetries between the outflows from the Northern Hemisphere and the Southern Hemisphere.
\end{abstract}

Keywords. Ionosphere (polar ionosphere) - magnetospheric physics (magnetosphere-ionosphere interactions; polar cap phenomena)

\section{Introduction}

The high-latitude ionosphere is an important source of plasma for the magnetosphere (Hultqvist, 1999; Yau and André, 1997). $\mathrm{O}^{+}$ions of ionospheric origin have been observed in the magnetospheric lobes (e.g. Sharp et al., 1981; Candidi et al., 1982, 1984; Seki et al., 1998) and in the plasma sheet (e.g. Peterson et al., 1981; Maggiolo and Kistler, 2014). There are three main regions of outflow at high latitudes: the auroral oval, the cusp, and the polar cap. The auroral oval and the cusp are regions of intense ion outflow in response to strong energy inputs like Poynting flux, particle precipitation, and the work done by strong field-aligned electric fields accelerating ions upwards (Lockwood et al., 1985; Zheng et al., 2005; Moore and Khazanov, 2010; Nilsson et al., 2012). In the absence of such energy inputs, the main source of energy for ion outflow in the polar cap is solar illumination.

Because the magnetic field above the polar caps is directly connected to the interplanetary magnetic field (IMF), Dessler and Michel (1966) argued that the ion temperature in the ionosphere is sufficiently high so that no hydrostatic equilibrium can be achieved there. The ions are more gravitationally bound, and will, together with the more easily escaping electrons, set up an ambipolar electric field parallel to the magnetic field lines, which accelerates ions upward (Axford, 1968; Banks and Holzer, 1968). This outflow is named the polar wind.

Compared to the outflow in the cusp and the auroral regions, the polar wind constitutes a mild but steady flux of ions into the magnetospheric lobes, emanating from a relatively large source area. Moreover, during geomagnetically quiet times, the polar cap is the main cold ion source for the magnetospheric lobes (Li et al., 2012). These ions have temperatures generally not much higher than the ion temperature in the ionosphere and flow at relatively small velocities (Engwall et al., 2009). As a consequence, they are very difficult to measure with satellites flying through the lobes, because these cold ions often have energies too low to overcome the spacecraft potential, which can go up to several tens of electronvolts in these regions. The low energization also means that it is very difficult for $\mathrm{O}^{+}$ions to escape Earth's gravitational potential via this mechanism, and so very little $\mathrm{O}^{+}$ 
is expected in the polar wind. Nevertheless, $\mathrm{O}^{+}$ions have been observed above the polar caps and in the lobes (Nagai et al., 1984; Waite Jr. et al., 1985; Abe et al., 1993; Su et al., 1998a). Many additional mechanisms have been proposed to explain this (see, e.g., Tam et al., 2007, for an overview).

Because they flow on open magnetic field lines, these ions can escape the magnetosphere into interplanetary space. In this way they may contribute to the erosion of the atmosphere. Their fate, however, is not certain. It has been argued that the final destination of these ions depends on the ratio of their velocity parallel to the magnetic field and the convection velocity perpendicular to the magnetic field (Ebihara et al., 2006; Haaland et al., 2012; Li et al., 2013), particularly during periods of southward IMF. Haaland et al. (2012) estimated that $90 \%$ of the ions flowing into the lobes are convected into the plasma sheet. There they can be recirculated into the inner magnetosphere and finally return to the atmosphere (Dungey, 1961; Seki et al., 2001) or ultimately be lost to interplanetary space (Slavin et al., 1989, 1999).

This is also true for the ions flowing out from the cusp. Many ions in the cusp are strongly energized and will leave the magnetosphere directly via the open magnetic field lines (Nilsson et al., 2012; Slapak et al., 2015). But the ions with the lowest energies may be convected across the polar cap and mix with the polar wind ions (e.g. Green and Waite Jr., 1985; Nilsson et al., 2012), so that it is not always possible to discern polar wind ions from the ions originating in the cusp. This also provides another possible explanation for the $\mathrm{O}^{+}$observed above the polar caps and in the lobes. Thus, in addition to outflowing ions from the auroral ovals, the polar wind and cusp outflow constitute an important source of plasma for the plasma sheet, since a part of these ions is convected there.

Whereas the ionosphere might be rivalled or even surpassed by the solar wind as a source of $\mathrm{H}^{+}$ions for the plasma sheet, there is a much larger proportion of $\mathrm{O}^{+}$in ionospheric outflow than in the solar wind, making it the dominant source of $\mathrm{O}^{+}$ions. The role of heavy ions like $\mathrm{O}^{+}$ is still hotly debated (see, for example, Daglis and Axford, 1996; Lotko, 2007; Kronberg et al., 2014), but they might be important for magnetospheric dynamics. Theoretical and modelling studies suggested an impact of $\mathrm{O}^{+}$ions on plasma sheet reconnection (Baker et al., 1982; Shay and Swisdak, 2004; Brambles et al., 2010). Some studies indicate that $\mathrm{O}^{+}$ ions can trigger substorms (Cladis and Francis, 1992; Yu and Ridley, 2013), and others that sawtooth events may be induced by ionospheric outflow (Brambles et al., 2011; Ouellette et al., 2013). Observational studies have not really been able to confirm nor refute this (e.g. Peterson, 2002; Kistler et al., 2006; Liao et al., 2014).

Ionospheric outflow, and especially the polar wind, can also be an important source of cold ions for the plasma sheet. It is generally assumed that the ions in the plasma sheet are quickly and efficiently heated (Gary, 1991; Delcourt et al., 1994; Arzner and Scholer, 2001), but some observations do observe a significant population of cold ions in the plasma sheet (Seki et al., 2003; Ebihara et al., 2008). If there are indeed cold ions in the plasma sheet, the polar wind would be one of the major suspects for the source, next to plasmaspheric winds and plumes. Toledo-Redondo et al. (2015) recently found, while studying reconnection at the dayside magnetopause, that cold ions introduce a new length scale in the reconnection process and thus may affect it.

Since solar illumination is the dominant energy source for the polar wind, the degree of solar illumination of the polar ionosphere should modulate the outflow. This has been evidenced by many observational studies and models (Abe et al., 1993; Su et al., 1998a, b; Glocer et al., 2012; Maes et al., 2015). Maes et al. (2015), studying outflow above smallscale polar cap arcs using Cluster (Escoubet et al., 2001) measurements, found that the upflow above the polar cap can be roughly divided into two distinct groups based on the solar zenith angle (SZA) of the footpoint of the field line in the ionosphere. The border between both was found to be around $\sim 100^{\circ}$, i.e. the solar zenith angle of the terminator at ionospheric altitude. The outflow was more intense for the group at smaller solar zenith angles than for the group at larger ones. The effect was found to be stronger for $\mathrm{O}^{+}$than for $\mathrm{H}^{+}$. The $\mathrm{O}^{+}$flux densities (normalized to $200 \mathrm{~km}$ altitude) ranged from $4.0 \times 10^{9}$ to $2.8 \times 10^{12} \mathrm{~m}^{-2} \mathrm{~s}^{-1}$, and were on average almost an order of magnitude smaller at the large solar zenith angle. The $\mathrm{H}^{+}$flux densities were between $8.6 \times 10^{11}$ and $1.1 \times 10^{13} \mathrm{~m}^{-2} \mathrm{~s}^{-1}$ and were on average almost a factor of 2 smaller above a dark ionosphere.

Since the rotational axis of the Earth is tilted by $\sim 23.4^{\circ}$ from the perpendicular on the ecliptic plane, the polar cap moves into and out of the sunlight during Earth's orbit around the Sun. The magnetic polar cap is not centred around the geographic poles but rather offset by several degrees latitude, adding a daily modulation to the magnetic polar cap's movement as it rotates in and out of the sunlight.

Earth's magnetic field is not symmetric between the Southern and Northern Hemisphere. The North Magnetic Pole, defined as the point in the Northern Hemisphere at the surface of the Earth where the magnetic field points exactly downwards, is located at $86.3^{\circ} \mathrm{N}$, as measured in 2015 (Thébault et al., 2015). The South Magnetic Pole, analogously defined, is not located at the opposite point in the Southern Hemisphere but at $64.3^{\circ} \mathrm{S}$ (Thébault et al., 2015). These positions are also not constant in time. This difference in offset implies that the northern and southern magnetic polar cap will receive different amounts of sunlight throughout the day and the year.

One would expect that these diurnal and seasonal variations in solar illumination of the polar caps, the fact that the terminator has a SZA larger than $90^{\circ}$, and the asymmetries in the magnetic field all have an effect on the total ion outflow and its composition. The goal of this paper is to qualitatively explore these effects. In the next section, we first explain the model we employ to study these effects. We report the results 
in Sect. 3, first for the simplest set-up: circular polar caps with a symmetric magnetic field (Sect. 3.1). Then we add the asymmetry of Earth's magnetic field (Sect. 3.2), and finally we use a more realistic polar cap shape (Sect. 3.3). This stepwise approach allows us to identify which cause has which effect. In Sect. 4 we discuss these results and their possible implications.

\section{Method}

To investigate the effects of the difference in outflow from a sunlit and a dark ionosphere, we keep things very simple. Inspired by the two regimes in upflowing ion fluxes above a sunlit and a dark ionosphere found by Maes et al. (2015), as discussed in the introduction, we assume that there are only two possible flux density values (ions $\mathrm{m}^{-2} \mathrm{~s}^{-1}$ ): one above a sunlit ionosphere and one above a dark ionosphere. Thus, we ignore all other factors that may have an influence on the outflow and cause a large natural spread, like variations in irradiance, flows, and density fluctuations in the neutral upper atmosphere, geomagnetic activity, etc. The eccentricity of Earth's orbit is also neglected.

For simplicity, we assume the transition between these two regimes to be sharp and located at a solar zenith angle of $100^{\circ}$. Therefore, mathematically, we define the flux density $f$ (ions $\mathrm{m}^{-2} \mathrm{~s}^{-1}$ ) as a step function:

$f=\left\{\begin{array}{ll}f_{\text {sun }} & \text { if } \mathrm{SZA} \leqslant 100^{\circ} \\ f_{\text {dark }} & \text { if } \mathrm{SZA}>100^{\circ}\end{array}\right.$.

Here $f_{\text {sun }}$ is the flux density above the sunlit ionosphere and $f_{\text {dark }}$ is that above the dark ionosphere. We take their values from the study in Maes et al. (2015) as the average value for upflow below SZA of $100^{\circ}$ and above $100^{\circ} . f_{\text {sun }}$ is equal to $3.3 \times 10^{11} \mathrm{~m}^{-2} \mathrm{~s}^{-1}$ and $f_{\text {dark }}$ is $4.4 \times 10^{10} \mathrm{~m}^{-2} \mathrm{~s}^{-1}$ for $\mathrm{O}^{+}$; for $\mathrm{H}^{+}$these are $3.2 \times 10^{12} \mathrm{~m}^{-2} \mathrm{~s}^{-1}$ and $1.7 \times 10^{12} \mathrm{~m}^{-2} \mathrm{~s}^{-1}$, respectively. The total ion flux from the whole polar cap, $F_{\text {tot }}$, is then simply found as follows:

$F_{\text {tot }}=f_{\text {sun }} \times A_{\text {sun }}+f_{\text {dark }} \times A_{\text {dark }}$,

where $A_{\text {sun }}$ is the area of the polar cap which is sunlit and $A_{\text {dark }}$ the area which is dark. Note that the flux densities are kept constant, but what does vary is the area of the polar cap which is sunlit and the area which is dark, on a diurnal basis, as the Earth rotates, and on a seasonal basis as the orientation of Earth's rotational axis changes with respect to the Sun. It is thus the variation in the sunlit fraction of the polar caps that introduces a time dependence into the total flux (as well as the size of the total polar cap in the third case, as explained further on).

Note that these flux densities from Maes et al. (2015) actually come from measurements of ion outflow above polar cap arcs. Since precipitating electrons caused by the polar cap arc system deposit energy in the ionosphere below, this might cause concern that these flux densities are not representative of the polar wind. Maes et al. (2015) argued to the contrary, since they found that the magnitude of the relatively small potential drop of the polar cap arcs (and thus the energy of the precipitating electrons) does not seem to have any discernable effect on the flux densities. The fact that the outflow is predominantly controlled by the ionospheric illumination conditions also indicates that the energy deposited in the ionosphere by precipitation in polar cap arcs plays a minor role. Moreover, integrated over the polar cap area, these $\mathrm{H}^{+}$flux densities lead to fluxes similar to those found by other studies of the polar wind (see e.g. Nagai et al., 1984; Cully et al., 2003; Huddleston et al., 2005; Engwall et al., 2009; André et al., 2015).

The $\mathrm{O}^{+}$fluxes fall at the lower end of the ranges found in literature (see, e.g., Yau et al., 1988; Cully et al., 2003), although it is often argued for these $\mathrm{O}^{+}$ions that they originate from more energetic sources like cusp outflow and are convected above the polar cap. In Maes et al. (2015) it is argued that this is most likely not the case for their data. Abe et al. (1993) also argued this for the $\mathrm{O}^{+}$ions they observed, and they found fluxes very similar to Maes et al. (2015). Nonetheless, even if the $\mathrm{O}^{+}$flux densities are not precise, the variations of the flux should still be correct, since they are caused by the alteration of the polar ionosphere by solar illumination, which happens regardless of the presence of polar cap arcs. Since the main goal of this paper is to give a qualitative analysis of the variations caused by the solar illumination, rather than to provide an accurate estimate of the ion flux, we proceed with these values.

In order to be able to distinguish between the consequences of the different causes mentioned in the introduction, we start with the simplest case of a circular magnetic polar cap, with perfect north-south symmetry. We assume the polar cap, bound by the auroral oval, to have "latitudinal radius" of $15^{\circ}$ and to be centred around the geomagnetic poles. The geomagnetic pole is defined as the point where the dipole axis of the magnetic dipole approximation intersects Earth's surface, and is located at $\sim 80^{\circ}$ geographic latitude (Thébault et al., 2015). It should be noted that the choice of the values of parameters like the SZA of the terminator and the size of the polar cap also affects the results.

After that we add a little more realism by introducing the north-south asymmetry in the magnetic field. We do this by centring the circular polar caps around the invariant magnetic poles (e.g. Emmert et al., 2010; Förster and Cnossen, 2013) instead of the geomagnetic poles. These are located at $82^{\circ} \mathrm{N}$ and $74^{\circ} \mathrm{S}$.

Finally we introduce a more realistic polar cap shape. To this end, we use the Tsyganenko 89 magnetic field model (Tsyganenko, 1989) and define the magnetic polar cap as the region poleward of the boundary between the open and closed magnetic field lines. This is found by starting at ionospheric altitude and following each magnetic field line to see whether it maps back into the ionosphere. In the T89 model 

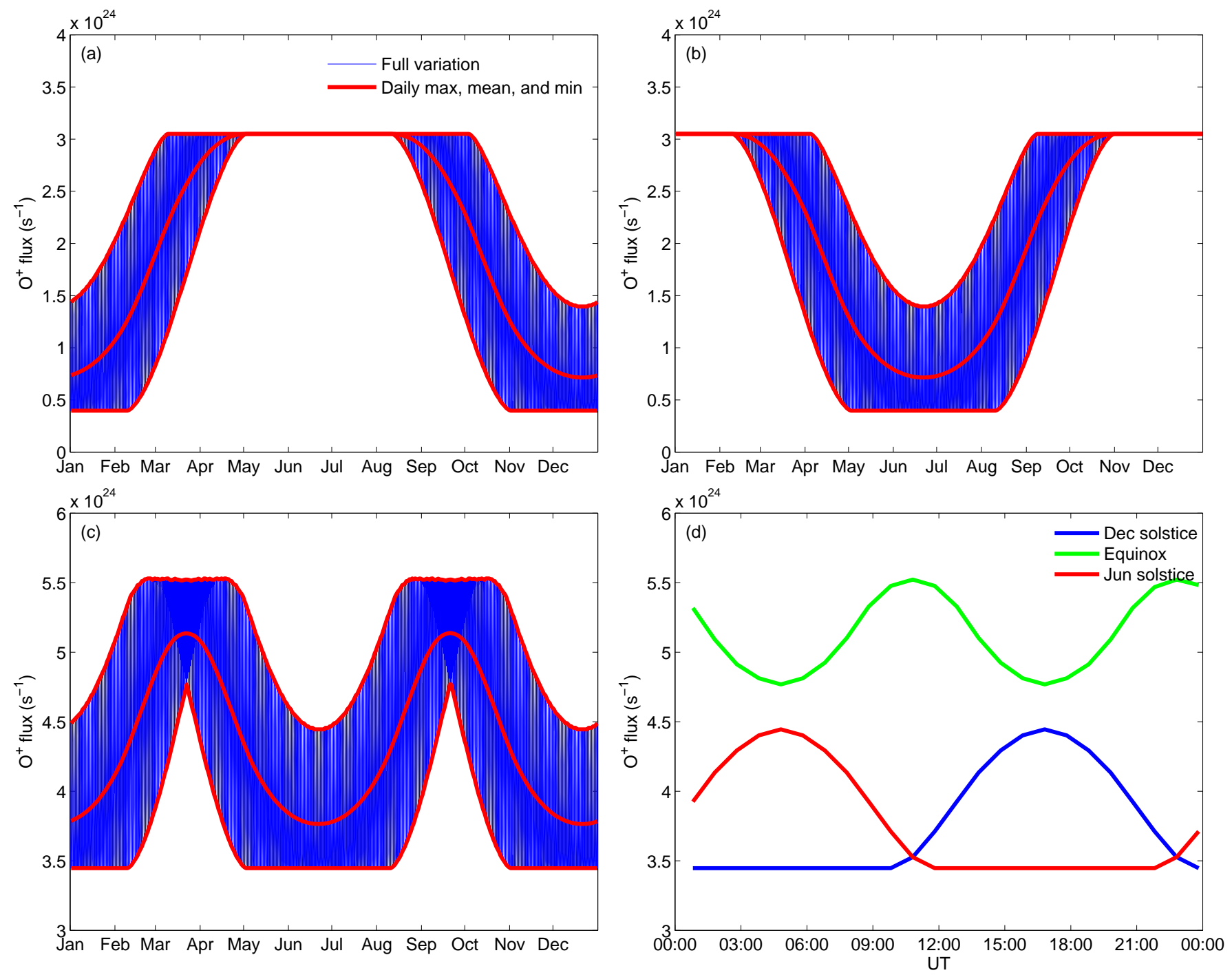

Figure 1. $\mathrm{O}^{+}$fluxes for a circular polar cap with north-south symmetry. (a) Northern Hemisphere. (b) Southern Hemisphere. (c) Both hemispheres combined. (d) UT dependence for both hemispheres combined.

a magnetic field line extending beyond $100 R_{\mathrm{E}}$ is cut off and considered open. The T 89 model requires the $\mathrm{Kp}$ value as an input parameterizing the geomagnetic activity; in this study we consider the case $\mathrm{Kp}=0$. While this may not be the most common geomagnetic condition, this seemed the most appropriate value as the polar cap shape is not correctly reproduced by $\mathrm{T} 89$ for higher $\mathrm{Kp}$.

\section{Results}

\subsection{Circular polar cap with north-south symmetry}

The $\mathrm{O}^{+}$fluxes from the northern and southern polar cap for circular polar caps with a symmetric magnetic field are shown in Fig. 1. The fluxes from both hemispheres, given in panel (a) and (b), are identical but shifted by half a year. It is clear that the flux from an individual hemisphere is highest around the summer solstice (around 21 June in the Northern Hemisphere, around 21 December in the Southern Hemisphere) and lowest around the winter solstice, as one would expect. The maximum number of $\mathrm{O}^{+}$ions is flowing out when the polar cap is completely sunlit $\left(F_{\text {tot }}=f_{\text {sun }} \times A_{\text {tot }}\right)$ and is $3.05 \times 10^{24} \mathrm{~s}^{-1}$, and the minimum when the polar cap is completely dark ( $F_{\text {tot }}=f_{\text {dark }} \times A_{\text {tot }}$ ), with only $3.97 \times$ $10^{23} \mathrm{~s}^{-1}$ flowing out. This is a variation of more than $600 \%$. The maximum of the daily average, which represents only the seasonal variation, is the same as the overall maximum, and the minimum of the daily average is $7.15 \times 10^{23} \mathrm{~s}^{-1}$. This is a variation of more than $300 \%$.

For $\mathrm{H}^{+}$the maximum is $2.96 \times 10^{25} \mathrm{~s}^{-1}$ and the minimum $1.57 \times 10^{25} \mathrm{~s}^{-1}$. For the daily average the minimum is $1.74 \times 10^{25} \mathrm{~s}^{-1}$. This corresponds to a variation of $\sim 90 \%$ 
and almost $\sim 70 \%$ respectively. The difference between the maximum and minimum flux is smaller than for $\mathrm{O}^{+}$, due to the smaller difference between the flux densities in sunlit and dark conditions for $\mathrm{H}^{+}$.

There is no daily variation in the flux in the period around the summer solstice. This is because, during this time, the magnetic polar cap is sunlit throughout the whole day (at ionospheric altitude) and thus, according to Eq. (2), the total flux is constant $\left(F_{\text {tot }}=f_{\text {sun }} \times A_{\text {tot }}\right)$. This can also be understood by simple reasoning: at the summer solstice, the geographic pole has a SZA of $90-23=67^{\circ}$. This means that the geomagnetic pole, offset from the geographic pole by $\sim 10^{\circ}$, will have a SZA of $67+10^{\circ}=77^{\circ}$ at its local midnight. With a magnetic polar cap with a "latitudinal radius" of $15^{\circ}$, the highest SZA found in the magnetic polar cap is therefore $77+15^{\circ}=92^{\circ}$. This indeed remains sunlit if the terminator is at a SZA of $100^{\circ}$. Analogously, one can find that around the winter solstice the polar cap is not completely dark throughout the whole day, with a terminator at $100^{\circ}$.

The largest daily variation occurs in the period before the spring equinox and after the autumn equinox (note that the daily variation is represented by the vertical distance between the upper and lower red line). At this time, the magnetic polar cap rotates into and out of the sunlight. There is still a daily variation around the winter solstice, but less than before and after, because the polar cap is completely dark during part of the day and never becomes fully sunlit.

When we combine the flux from both hemispheres, a daily and a seasonal variation persist (see panel (c) of Fig. 1). Because the terminator has a SZA larger than $90^{\circ}$, the proportion of the polar cap receiving sunlight in one hemisphere is not the opposite of that in the other. Therefore, the variations in one hemisphere do not cancel those in the other hemisphere. There is no difference between the two solstices, but there is still a seasonal variation from equinox to solstice. The largest flux from both hemispheres combined, $5.53 \times 10^{24} \mathrm{~s}^{-1}$ for $\mathrm{O}^{+}$and $5.62 \times 10^{25} \mathrm{~s}^{-1}$ for $\mathrm{H}^{+}$, occurs at the equinox and the lowest, $3.45 \times 10^{24} \mathrm{~s}^{-1}$ for $\mathrm{O}^{+}$and $4.53 \times 10^{25} \mathrm{~s}^{-1}$ for $\mathrm{H}^{+}$, at the solstice. This is a variation of $\sim 60$ and $\sim 24 \%$ for $\mathrm{O}^{+}$and $\mathrm{H}^{+}$, respectively. For the daily average this variation is $\sim 36$ and $\sim 15 \%$, respectively.

In panel (d) of Fig. 1 we see the UT dependence of the flux from both hemispheres combined, in red for the June solstice, in blue for the December solstice, and in green for the equinox. In June, there is a peak at 16:48 UT. This is at the local noon of the south geomagnetic pole, which is entering its winter and receiving its daily amount of sunlight in that season. During the solstice, the summer hemisphere does not add to the daily variation, because it is completely sunlit during the whole day. Therefore, all the variation is due to the winter hemisphere, which increases the total combined flux when it receives sunlight (from $\sim$ 10:00 until $\sim 23: 00 \mathrm{UT}$ in the north and from $\sim 22: 00$ until $\sim$ 11:00 UT in the south). Consequently, the flux is constant at $3.45 \times 10^{24} \mathrm{~s}^{-1}$ for $\mathrm{O}^{+}$ and $4.53 \times 10^{25} \mathrm{~s}^{-1}$ for $\mathrm{H}^{+}$when the polar cap in the winter hemisphere is completely dark. It is maximum when the illuminated proportion of the polar cap in the winter hemisphere is maximum (i.e. local noon): $4.45 \times 10^{24} \mathrm{~s}^{-1}$ for $\mathrm{O}^{+}$and $5.05 \times 10^{25} \mathrm{~s}^{-1}$ for $\mathrm{H}^{+}$. Thus, the combined $\mathrm{O}^{+}$flux varies with about $29 \%$ throughout the day at solstice, while for $\mathrm{H}^{+}$ this variation is of the order of $12 \%$.

At equinox there are two minima, $4.77 \times 10^{24} \mathrm{~s}^{-1}$ for $\mathrm{O}^{+}$ and $5.22 \times 10^{25} \mathrm{~s}^{-1}$ for $\mathrm{H}^{+}$, which coincide with the local noon and midnight at the magnetic poles. The maxima, $5.61 \times 10^{24} \mathrm{~s}^{-1}$ for $\mathrm{O}^{+}$and $5.64 \times 10^{25} \mathrm{~s}^{-1}$ for $\mathrm{H}^{+}$, happen at the local morning and evening of the poles at $\sim 10: 48$ and $\sim 22: 48$ UT. Therefore, the maximum outflow at the equinox does not occur during noon at the poles but instead in the morning and evening when the illumination of both polar caps combined is maximized.

\subsection{Circular polar cap with north-south asymmetry}

We now introduce the asymmetry of the magnetic field by centring the polar caps around the invariant magnetic poles. The resulting number fluxes for $\mathrm{O}^{+}$behave as shown in Fig. 2. The southern magnetic polar cap is then located at lower geographic latitudes, and will sway farther into and out of the darkness. The consequence is immediately visible: in the Southern Hemisphere (in panel b) there is a much larger daily variation at the winter solstice and the equinoxes. There are now even two periods (in April and September) where the flux goes from the maximum (when completely sunlit) to the minimum value (when completely dark) in one day. Whether this happens also depends on the actual size of the polar cap and the position of the terminator. Since the north magnetic polar cap is now centred at higher latitudes, there is less variation in the flux from the Northern Hemisphere (panel a).

Another interesting point is that the daily mean flux from the southern polar cap in the local winter is higher than that from the northern polar cap in winter. This is the case during the whole period of approximately 65 days before and after the local winter solstices. The southern daily average flux is higher at the winter solstice because, due to its larger offset, the southern polar cap will be able to spend more time sunward of the terminator. The difference in the daily average flux at the local winter is at its largest at $\sim 38 \%$ for $\mathrm{O}^{+}$ and $\sim 8 \%$ for $\mathrm{H}^{+}$. In the following $\sim 91.5$ days, including the equinox, the daily average flux in the Northern Hemisphere is larger, with the difference peaking at $\sim 11 \%$ for $\mathrm{O}^{+}$and $\sim 6 \%$ for $\mathrm{H}^{+}$. This happens because, during this period, the northern polar cap less often reaches the darkness owing to its smaller offset. In the period of $\sim 26$ days before and after the local summer solstice, the fluxes from both hemispheres are equal. At this time both polar caps are completely sunlit throughout the whole day and the flux is maximized $\left(F_{\text {tot }}=A_{\text {tot }} \times f_{\text {sun }}\right)$. For the next $\sim 91.5$ days, the Northern Hemisphere has a higher flux again. Thus, the difference between the outflow from both hemispheres due to the asymmetry in the magnetic field itself has a seasonal vari- 

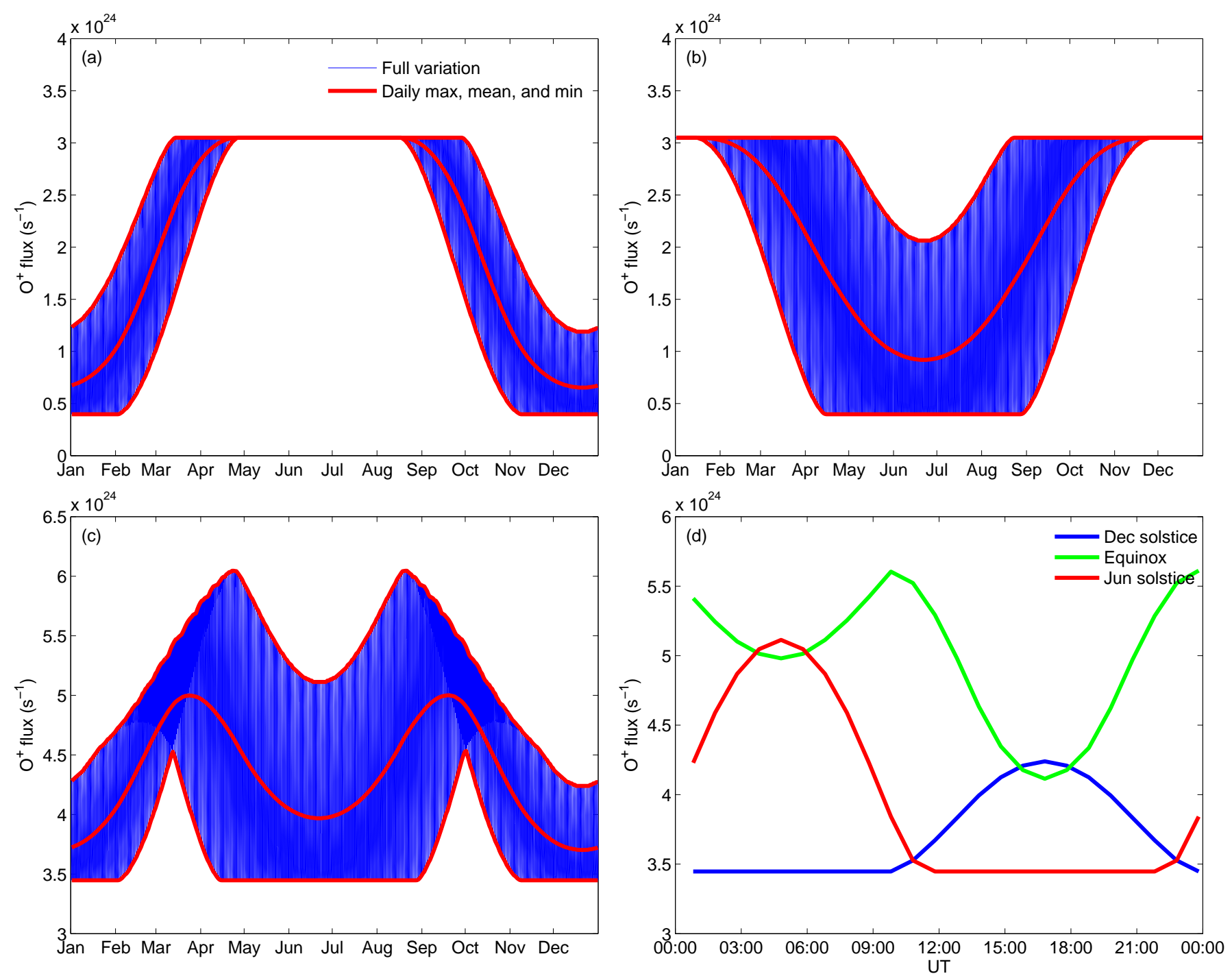

Figure 2. $\mathrm{O}^{+}$fluxes for a circular polar cap with north-south asymmetry. (a) Northern Hemisphere. (b) Southern Hemisphere. (c) Both hemispheres combined. (d) UT dependence for both hemispheres combined.

ation. Both trends oppose each other so that the difference between the average flux over the whole year from the northern and southern polar cap becomes almost, but not exactly, zero.

Panel (c) of Fig. 2 shows the total flux from both hemispheres combined. As in the symmetric case, there is still a seasonal variation. The shape is different, however. The peaks of the daily maximum are not at the equinoxes anymore but closer to the June solstice, namely at 22 April and 21 August. The peaks of the daily mean are still at the equinox. The fluxes are now also not symmetric anymore between both solstices. The Southern Hemisphere's higher daily mean in its winter than that in the north means that the combined flux is higher at the June solstice, $3.97 \times 10^{24} \mathrm{~s}^{-1}$ for $\mathrm{O}^{+}$and $4.80 \times 10^{25} \mathrm{~s}^{-1}$ for $\mathrm{H}^{+}$, than at the December solstice, $3.70 \times 10^{24} \mathrm{~s}^{-1}$ for $\mathrm{O}^{+}$and $4.66 \times 10^{25} \mathrm{~s}^{-1}$ for $\mathrm{H}^{+}$.
This is a difference of more than $7 \%$ and for $\mathrm{O}^{+}$and almost $3 \%$ for $\mathrm{H}^{+}$.

In panel (d) of Fig. 2 the UT variation in the outflowing fluxes is shown for this asymmetric case. Contrary to the symmetric hemispheres, the daily peak does not have the same magnitude at the two solstices. This is also visible in panel (c). For $\mathrm{O}^{+}$this is $5.11 \times 10^{24} \mathrm{~s}^{-1}$ in June and $4.24 \times 10^{24} \mathrm{~s}^{-1}$ in December, and for $\mathrm{H}^{+}$this is $5.40 \times$ $10^{25} \mathrm{~s}^{-1}$ and $4.94 \times 10^{25} \mathrm{~s}^{-1}$, respectively. At equinox, the two daily minima also do not have the same depth. They are for $\mathrm{O}^{+} 4.98 \times 10^{24} \mathrm{~s}^{-1}$ and $4.11 \times 10^{24} \mathrm{~s}^{-1}$, respectively, and $5.32 \times 10^{25} \mathrm{~s}^{-1}$ and $4.88 \times 10^{25} \mathrm{~s}^{-1}$ for $\mathrm{H}^{+}$. Note that the two peaks at equinox are not separated by half a day, occurring around $\sim 10: 00$ and $\sim 00: 00$ UT. 

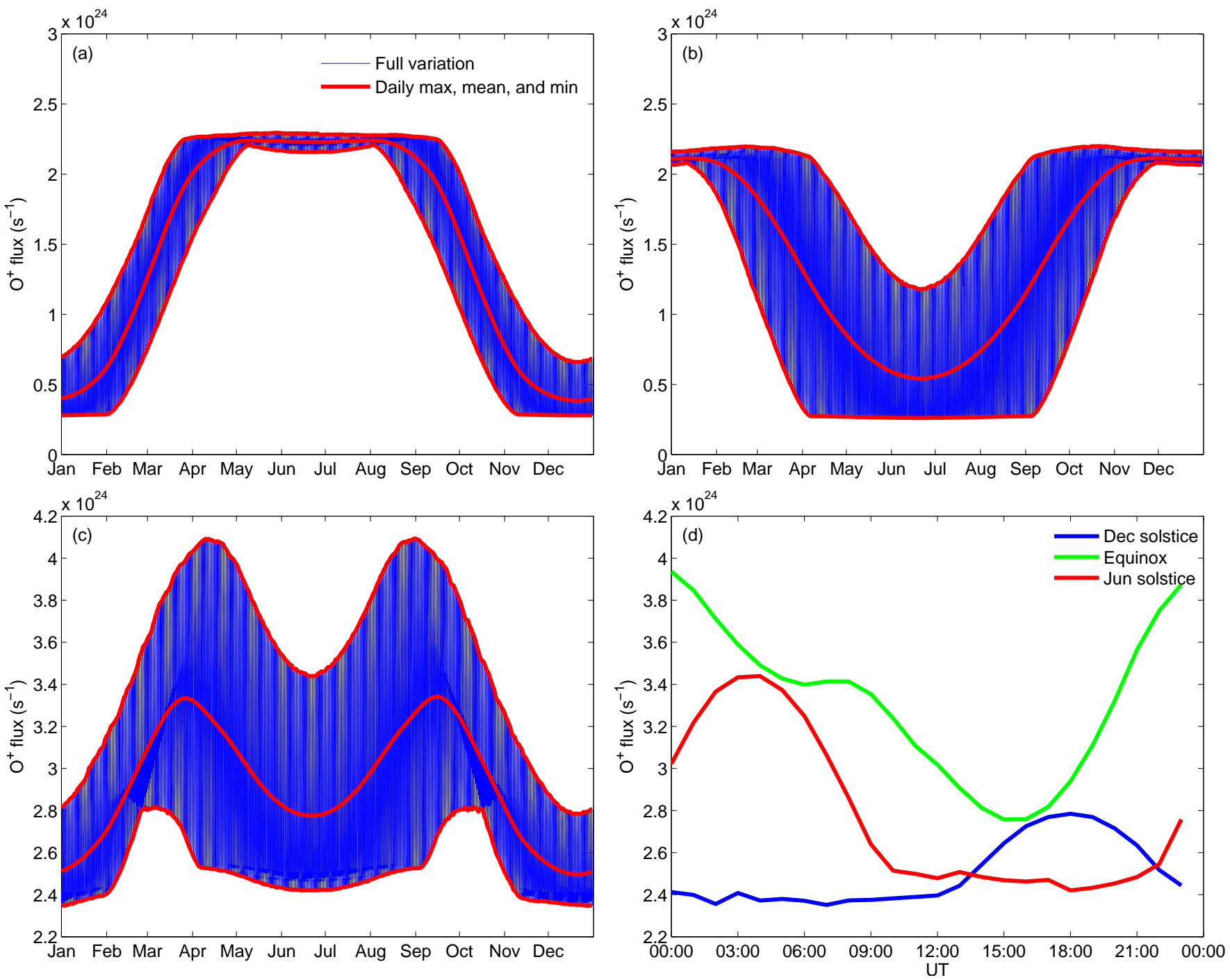

Figure 3. $\mathrm{O}^{+}$fluxes for a polar cap from the Tsyganenko model. (a) Northern Hemisphere. (b) Southern Hemisphere. (c) Both hemispheres combined. (d) UT dependence for both hemispheres combined.

\subsection{Realistic polar cap shape: T89}

In order to asses the effect of a more realistic polar cap shape, we use the Tsyganenko 89 model for $\mathrm{Kp}=0$ to obtain the open-closed boundary. The resulting $\mathrm{O}^{+}$fluxes are plotted in Fig. 3. One of the main differences with the earlier cases is that overall the flux is lower. This is because the area of the magnetic polar cap found for $\mathrm{Kp}=0$ with the T89 model is significantly smaller than that of a circular polar cap down to $75^{\circ}$ MLAT. This is related to our choice of considering the polar cap for low activity and because of the issues with higher activity mentioned in Sect. 2. For higher activity levels, the polar cap area increases significantly, and together with it the total flux.

Another effect that is immediately clear, which does not appear in the circular case, is that there is still a daily varia-

tion during the period around the summer solstice. The magnetic polar cap is still completely sunlit during the whole day at the summer solstice, so this is not what is causing this variation. According to the Tsyganenko model, the magnetic polar cap varies throughout the day in shape and area. The variation is small and relatively irregular. That is what causes the variation in flux during the summer.

When we look at the combined flux from both hemispheres, plotted in panel (c) of Fig. 3, we see that it has a somewhat different shape from the circular asymmetric case, but overall it looks quite similar. One clear difference is that the daily minimum behaves a bit differently and is not flat around the solstices but dips even further. This is again the effect of the variation in polar cap size.

We also show the fluxes of $\mathrm{H}^{+}$in Fig. 4. We do this because in this case, as opposed to the circular cases where $\mathrm{H}^{+}$ 

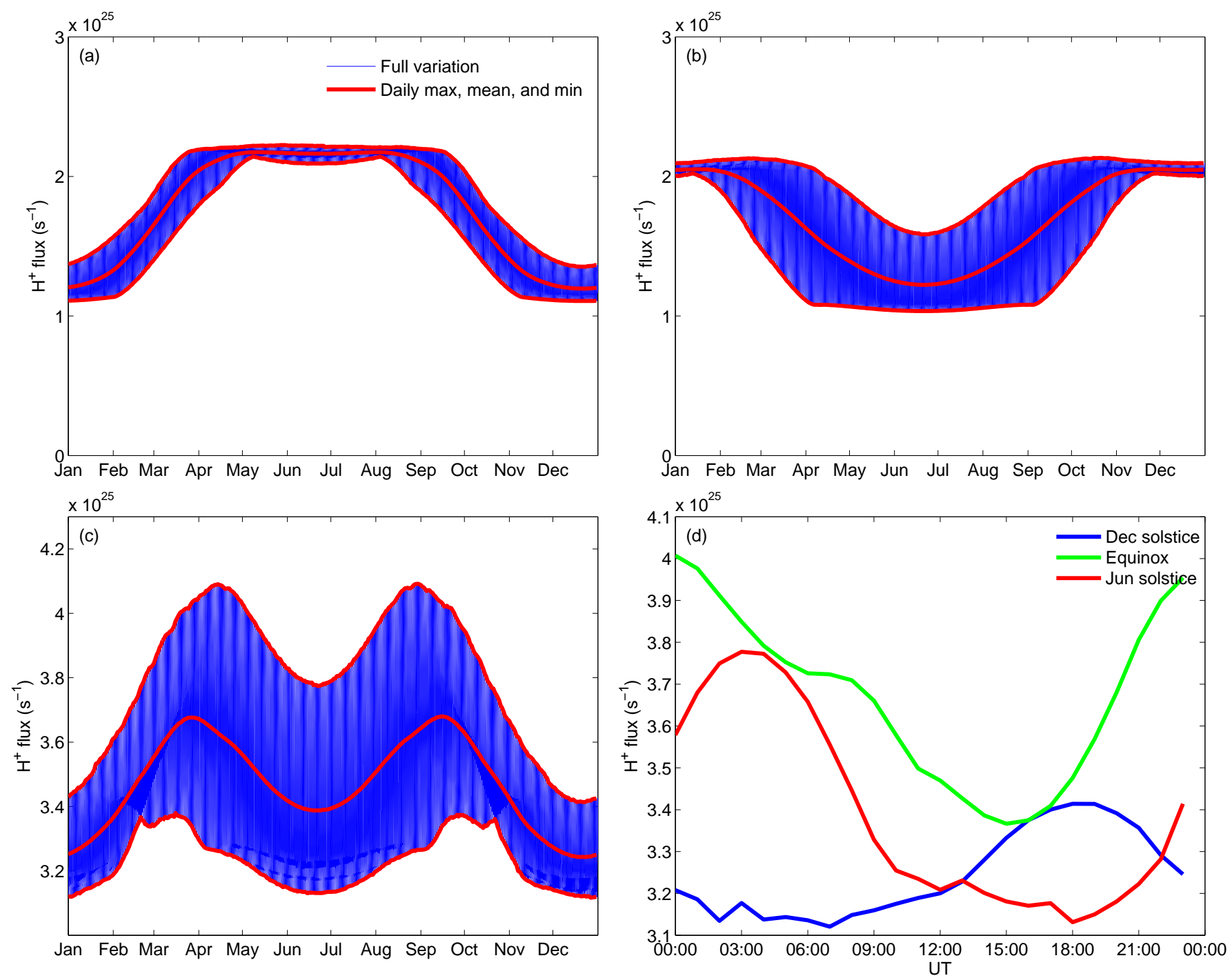

Figure 4. $\mathrm{H}^{+}$fluxes for a polar cap from the Tsyganenko model. (a) Northern Hemisphere. (b) Southern Hemisphere. (c) Both hemispheres combined. (d) UT dependence for both hemispheres combined.

behaves the same way as $\mathrm{O}^{+}$except having smaller variations, $\mathrm{H}^{+}$exhibits a somewhat different behaviour than $\mathrm{O}^{+}$. This is because the total area of the polar cap also varies. The effect of the solar illumination is smaller for $\mathrm{H}^{+}$, since the difference between $f_{\text {sun }}$ and $f_{\text {dark }}$ is smaller than for $\mathrm{O}^{+}$, but the effect of the varying polar cap area is the same for both $\mathrm{H}^{+}$and $\mathrm{O}^{+}$.

The $\mathrm{H}^{+}$flux from both hemispheres shows a variation of $\sim 31 \%$, with a maximum of $4.09 \times 10^{25} \mathrm{~s}^{-1}$ and a minimum of $3.12 \times 10^{25} \mathrm{~s}^{-1}$. For the daily average, going from $3.68 \times 10^{25} \mathrm{~s}^{-1}$ down to $3.24 \times 10^{25} \mathrm{~s}^{-1}$, the variation is around $\sim 13 \%$. $\mathrm{O}^{+}$is more strongly affected by solar illumination and thus the flux shows larger variations going from $4.09 \times 10^{24} \mathrm{~s}^{-1}$ down to $2.35 \times 10^{24} \mathrm{~s}^{-1}$; this is a variation of $\sim 74 \%$, and $\sim 34 \%$ for the daily average, which has a maximum and minimum of $3.34 \times 10^{24}$ and $2.50 \times 10^{24} \mathrm{~s}^{-1}$. Since the outflows of $\mathrm{O}^{+}$and $\mathrm{H}^{+}$react differently to solar illumination, the fraction of $\mathrm{O}^{+}$in the outflow will also vary. This fraction may vary from $\sim 7.0$ to $\sim 9.1 \%$, which is a variation of $\sim 31 \%$, and the daily average from $\sim 7.1$ to $\sim 8.3 \%$, which is a variation of $\sim 16 \%$. The total ion flux is dominated by $\mathrm{H}^{+}$and will thus show variations similar to the $\mathrm{H}^{+}$ flux, namely $\sim 34$ and $\sim 15 \%$ for the daily average. However, since the mass of the $\mathrm{O}^{+}$ion is about 16 times higher than that of the $\mathrm{H}^{+}$ion, the contribution of the $\mathrm{O}^{+}$outflow to the total mass flux may be more significant. For the mass flux from both hemispheres combined we find that there are variations of up to $\sim 55 \%$, and up to $\sim 25 \%$ for the daily average.

We also find a different behaviour in the UT variation in panel (d) of Fig. 3. The two peaks at equinox are in this case very different and again shifted. The one before at $\sim 7$ UT is 
with $3.41 \times 10^{24} \mathrm{~s}^{-1}$ much lower than the one at midnight, $3.94 \times 10^{24} \mathrm{~s}^{-1}$, and is barely higher than the local minimum only $1 \mathrm{~h}$ before, with $3.40 \times 10^{24} \mathrm{~s}^{-1}$. In the $\mathrm{H}^{+}$flux in panel (d) of Fig. 4, it is no longer even a local maximum. Like in the previous case, the two minima do not have the same depth, but now they also do not occur at the local noon of the poles, but around $\sim 6$ and $\sim 15 \mathrm{UT}$.

The polar caps found from the Tsyganenko model do not have the same area in both hemispheres. On average the polar cap is $\sim 5.8 \%$ larger in the north than in the south. Consequently, the average flux over the whole year from the Northern Hemisphere is $\sim 6.7 \%$ larger than that from the Southern Hemisphere for $\mathrm{O}^{+}$and $\sim 6.2 \%$ for $\mathrm{H}^{+}$. This can be seen in panels (a) and (b) of Fig. 4, if one looks closely. The daily averages are also not equal around the local summer solstices in this case, and around the local winter solstices the $\mathrm{H}^{+}$flux from the Southern Hemisphere is almost equal to that from the Northern Hemisphere ( $\sim 2 \%$ larger at maximum).

\section{Discussion}

The set-up of this simple model neglects many factors which influence the outflowing flux, like UV intensity, geomagnetic activity, heating of the atmosphere, neutral winds, etc. Their effects should be superimposed on the model results presented here. However, according to observations, the outflowing flux densities should statistically be separable in two groups by the solar zenith angle of their ionospheric origin, with the group with lower SZA having a higher average flux than the other. Therefore, these results should apply to the fluxes averaged over these other conditions.

\subsection{Combined flux from both hemispheres}

An important result, showing up in all three cases, is that, when combining the total flux coming from both hemispheres, we still see a seasonal and diurnal variation. For the circular and symmetric case, the seasonal variation is caused (only) by the fact that the terminator at ionospheric altitudes has a SZA larger than $90^{\circ}$. This means that the illumination profile of one magnetic polar cap is not the inverse of that of the other, and thus the variations in the flux from both hemispheres do not cancel each other. The fact that the geographic pole and the magnetic pole are not located at the same position implies that this also causes diurnal variations in the summed flux.

For the asymmetric case this also happens, but the asymmetry in the offset of both polar caps is an extra cause of seasonal variation in the summed outflow from both hemispheres. Even with a terminator at $90^{\circ}$, there are still variations over the seasons and days, whereas in the symmetric case the flux would remain constant over the whole year with the terminator at $90^{\circ}$. The variations due to this effect are comparable to those due to the terminator effect, if not a bit larger. In terms of daily averages (and thus the seasonal variation) they are smaller, however, about $\sim 50 \%$. Note also that these variations due to both causes do not always occur at the same time, so they may combine to a larger variation at some times or counteract each other at other times.

For the calculations with the polar cap shapes from the Tsyganenko model, the north-south asymmetry in the polar cap area and the variation in the area constitute again two extra causes of seasonal variation for the total combined flux.

\subsection{Importance to magnetospheric dynamics}

The variation in the combined flux is important because a large fraction of the ions in the polar wind flow into the plasma sheet (Haaland et al., 2012; Li et al., 2013). This combined flux thus also represents to some extent the supply of ions from the polar ionosphere to the plasma sheet. Consequently, this may lead to seasonal and diurnal variations in the plasma sheet density or composition. The high latitude ionosphere is an important source of plasma for the plasma sheet, more specifically of $\mathrm{O}^{+}$ions. The polar wind is also an important source of cold ions. As discussed in the introduction, the role of heavy ions like $\mathrm{O}^{+}$in magnetospheric dynamics is not yet clear, as is the answer to the question of whether ions can remain cold in the plasma sheet, but both cold ions and $\mathrm{O}^{+}$ions (cold or not) may affect reconnection or the stability in the tail.

Geomagnetic activity has been clearly observed to exhibit seasonal behaviour. One well-documented example is the occurrence frequency of geomagnetic storms, which has two peaks per year, at the equinoxes (e.g. Sabine, 1856; Cliver et al., 2000; Echer et al., 2011). This seasonal behaviour is often attributed to the Russell-McPherron mechanism (Russell and McPherron, 1973). This states that the inclination of the Sun's equatorial plane and the inclination of Earth's rotational axis from Earth's orbital plane cause a bias toward larger absolute IMF $B_{z}$ values (in the GSM coordinate system) around the equinoxes and thus a higher geo-effectiveness. However, it has been argued that this mechanism cannot account for the full variation (Cliver et al., 2000). Other mechanisms have been suggested (see, e.g., Russell and McPherron, 1973; Tsurutani and Gonzalez, 1995; Cliver et al., 2000, for a discussion of some).

The two peaks at the equinoctial months observed in the occurrence of geomagnetic storms coincide with the two peaks found in this study for the combined ion outflow from both polar caps. At this time of the year the total ion flux from both hemispheres peaks, as well as the $\mathrm{H}^{+}$flux, the $\mathrm{O}^{+}$flux, the $\mathrm{O}^{+}$proportion, and the mass flux. If $\mathrm{O}^{+}$indeed can alter geomagnetic activity, seasonal variations in ionospheric outflow should perhaps also be considered as a possible explanation. The same can be said if cold ion outflow can indeed remain cold in the plasma sheet. 


\subsection{Variations compared to other effects}

Ion outflow from the polar ionosphere can also vary due to geomagnetic activity and variations in solar EUV (extreme ultraviolet) intensity. For geomagnetic activity, the outflowing $\mathrm{H}^{+}$flux density $\left(\mathrm{m}^{-2} \mathrm{~s}^{-1}\right)$ is found to increase by $\sim 300 \%$ from low to high Kp (Yau et al., 1988; Cully et al., 2003; Engwall et al., 2009), and the $\mathrm{O}^{+}$outflow rate even by $\sim 2000 \%$ (Yau et al., 1988; Cully et al., 2003). Haaland et al. (2015), studying cold outflowing ions during geomagnetic storms (identified by their excursion in Dst), find a similar number with an increase of up to $\sim 300 \%$ the average non-storm-time outflow rate during the peak phase.

The effect of the intensity of the EUV flux coming from the Sun has also been studied. Yau et al. (1988) actually found a (statistically marginal) decrease of $\sim 50 \%$ for $\mathrm{H}^{+}$ with DE 1 data. For $\mathrm{O}^{+}$, an increase of $\sim 400 \%$ was found. Cully et al. (2003) using Akebono data, however, observed an increase for both $\mathrm{H}^{+}$and $\mathrm{O}^{+}$, of $\sim 300$ and $\sim 2000 \%$, respectively. Furthermore, Engwall et al. (2009) and André et al. (2015) found an increase of the ion total flux of $\sim 200$ and $\sim 100 \%$, respectively. It is worth mentioning that Yau et al. (1988) and Cully et al. (2003) were restricted to an energy range of $\sim 10 \mathrm{eV}-17 \mathrm{keV}$ and $\sim 1-70 \mathrm{eV}$, respectively, and Engwall et al. (2009) and André et al. (2015), using an indirect method involving the spacecraft potential, should have theoretically observed all ions. However, the last of these methods can only be used when the thermal energy of the ions is lower than both their bulk kinetic energy and the energy needed to overcome the spacecraft potential. Therefore, this method only observes ions with energies below Cluster's typical spacecraft potential in the lobes $(\sim 40-60 \mathrm{~V})$.

The variations found in this study, due to the presence or absence of solar illumination, are for the $\mathrm{H}^{+}$flux from one hemisphere roughly $\sim 2$ times smaller than those found due to geomagnetic activity and solar EUV intensity. For $\mathrm{O}^{+}$ they are roughly a factor of $\sim 3$ smaller. When combining the flux from both hemispheres, the variations in this study become much smaller, since the illumination of one hemisphere opposes that of the other to some extent. However, compared to variations due to geomagnetic activity, those found in this study constitute an increase over an extended period of time (they can last up to several months). In other words, it is a steady increase that may lead to mass loading of the plasma sheet. This difference may lead, for example, to an extra of $\sim 2.7 \times 10^{31}$ ions, of which $\sim 4.4 \times 10^{30}$ are $\mathrm{O}^{+}$ions, or $\sim 1.5 \times 10^{5} \mathrm{~kg}$ escaping from the ionosphere and possibly ending up in the plasma sheet - during the 3 months around the equinox compared to the outflow during the 3 months around the December solstice. Moreover, in the context of the importance of ionospheric outflow for magnetospheric dynamics, it is difficult to causally link an increase in geomagnetic activity to the increase in ionospheric outflow caused by increased geomagnetic activity. The variations in outflow found in this study may happen before geomagnet- ically active times. Variations in F10.7 follow the 11-year solar cycle but also occur on smaller timescales. However, these variations do not have a daily or seasonal periodicity.

To put these numbers into context, we can very roughly estimate the total plasma content in the plasma sheet. Using the formula for $\mathrm{H}^{+}$and $\mathrm{O}^{+}$densities in the midtail plasma sheet of Maggiolo and Kistler (2014), with an average F10.7 of 150 and $\mathrm{Kp}$ of 2 (the values used in this study come from a study during low activity), we find an average $\mathrm{H}^{+}$density of $\sim 0.26 \mathrm{~cm}^{-3}$ and $\mathrm{O}^{+}$density of $\sim 3.8 \times 10^{-3} \mathrm{~cm}^{-3}$. Using a total plasma sheet volume of $\sim 4 \times 10^{24} \mathrm{~m}^{3}$ from Chappell et al. (1987), we find a total of $\sim 1.0 \times 10^{30}$ ions in the plasma sheet, of which $\sim 1.5 \times 10^{28}$ are $\mathrm{O}^{+}$ions, and a total mass of $\sim 2.1 \times 10^{3} \mathrm{~kg}$. Therefore, the additional outflow during the trimester around equinox is $\sim 26$ times larger than the total content of the plasma sheet in terms of number of ions, and $\sim 73$ times in terms of mass. The additional number of $\mathrm{O}^{+}$ions is more than $\sim 291$ times the $\mathrm{O}^{+}$ions in the plasma sheet during quiet times. In other words, since these 3 months are 90 days, on average the content of almost one additional plasma sheet per day flows out from the polar cap around the equinox compared to around the December solstice, in terms of mass, and more than $\sim 3$ additional plasma sheets per day in terms of $\mathrm{O}^{+}$ion numbers. This all assumes that the $\mathrm{O}^{+}$ flux densities used are representative of the polar wind.

The variations due to the polar cap being sunlit or dark, represent a modulation of the background outflow, so these variations should also be factored in with the variations due to geomagnetic activity and solar EUV intensity. It has to be noted that the eccentricity of Earth's orbit, which was neglected in these calculations, also causes a seasonal variation. The current eccentricity of Earth's orbit is $\sim 0.0167$; therefore, the intensity of the solar illumination is $\sim 6.9 \%$ higher at perigee than at apogee. It is, however, difficult to translate this intensity variation into an increase in outflowing ion flux

\subsection{North-south asymmetry in outflow}

As mentioned in Sect. 3, the outflow from both hemispheres is expected to be different, due to the asymmetry in the magnetic field. As we found from the asymmetric circular case and the more realistic case, there are two causes for the asymmetry: the difference in the offset of the magnetic pole from the rotational axis and the difference in polar cap area.

The asymmetry in the flux resulting from the difference in offset has itself a seasonal variation. At the local winter solstice, the southern hemisphere has a larger average outflow, because the larger offset from the rotational axis means that the polar cap is more likely to still reach the sunlight. However, around the equinoxes the flux from the Northern Hemisphere becomes larger. This means that, counterintuitively, in the period around the equinoxes there is also an asymmetry in the fluxes. Over the whole year these tend to cancel each other out. However, which hemisphere has the largest average flux over the whole year, as well as the magnitude of the 
difference, depends on the precise values for the size of the auroral oval and the SZA of the terminator. This dependence is not simple; it is not even monotonous. When changing the position of the terminator and the size of the circular polar caps over a range of values, the difference in average flux over the whole year can go up to a few percent for the $\mathrm{O}^{+}$ flux, and almost $1.5 \%$ for $\mathrm{H}^{+}$. When comparing the daily averages (in terms of days after the local winter solstice) the difference can go up to almost $150 \%$ for $\mathrm{O}^{+}$and more than $20 \%$ for $\mathrm{H}^{+}$.

When using the polar caps from the Tsyganenko model, we find a larger area for the northern polar cap. This does not have a seasonal variation but rather shifts the flux from the Northern Hemisphere upwards by a few percent over the whole year. This difference in flux is not due to a difference in solar illumination but instead to a difference in the size of the source area. This difference in polar cap area is a result of the asymmetry in Earth's magnetic field, which is not a perfect dipole and not centred around Earth's centre of mass. There is no a priori reason why this difference in area should persist at high altitudes and cause a difference between the cross section area of the northern and southern magnetospheric lobes, since the higher-order terms of the multipolar expansion of the magnetic field fall off rapidly with distance. Thus, if we assume the asymmetry in Earth's magnetic field dies off at higher altitudes, and neglect any possible external source of asymmetries, the smaller total flux in the south would flow into the same area in the lobes as the higher flux in the north. In this case, not only will the total flux (ions $\mathrm{s}^{-1}$ ) be lower in the south but also the flux density (ions $\mathrm{m}^{-2} \mathrm{~s}^{-1}$ ).

\subsection{Observability}

One can argue that the variations and asymmetries discussed in this study should be visible to some extent in an extensive statistical study of in situ observations of the flux densities in the magnetospheric lobes, despite the fact that we only discussed the total flux. If a statistical study uses a dataset that sufficiently samples the whole polar cap, so that the average is representative of the flux density everywhere in the polar cap, then this average flux density is equal to the total flux divided by the polar cap area. Therefore, the average flux density should also exhibit the temporal variations and the asymmetries of the total flux. We should note, however, that this requires a very good sampling of the whole polar cap. Moreover, for temporal variations, this should be true at all time (down to the relevant timescale). This is a very strong requirement, and one which is rarely (or never) achieved in a realistic dataset of satellite measurements. Nonetheless, even if not all variations are visible, some might still show up in a sufficiently large dataset. For example, a study probing the flux densities in the magnetospheric lobes with enough measurements will most likely observe seasonal variations. Such studies might also be able to find an asymmetry in the outflow from both hemispheres.

\section{Conclusions}

With a simple set-up, this study explored the consequences of solar illumination modulation of ionospheric outflow above the polar cap as the magnetic polar cap rotates in and out of the sunlight on a diurnal and seasonal basis. The main results can be summarized as follows:

- There are daily and seasonal variations in the ion flux from each polar cap.

- These variations persist when summing the flux from both hemispheres, with maxima at the equinoxes. There are three main causes for this:

- the fact that the terminator at ionospheric altitude has a solar zenith angle around $100^{\circ}$,

- the larger offset of the southern polar cap from the rotational axis due to the north-south asymmetry of Earth's magnetic field,

- the north-south asymmetry in the area of the magnetic polar cap.

- These variations also modulate the supply to the plasma sheet, and possibly affect magnetospheric dynamics. The peaks in combined outflow coincide with the peaks of geomagnetic storm occurrence at the equinoxes, suggesting that the variations may be a cause for seasonal variation in geomagnetic activity.

- The north-south asymmetry in Earth's magnetic field also causes north-south asymmetries in the outflowing ion fluxes from the polar cap.

Acknowledgements. This work was supported by the IAP network "Planet TOPERS" (P7/15) initiated by the Belgian Science Policy Office (BELSPO). Romain Maggiolo was supported by Cluster/PRODEX PEA 40001009739.

We acknowledge the support from the International Space Science Institute through funding of their international team on "Magnetosphere-ionosphere-thermosphere coupling: differences and similarities between the two hemispheres".

The topical editor, Y. Miyoshi, thanks two anonymous referees for help in evaluating this paper.

\section{References}

Abe, T., Whalen, B. A., Yau, A. W., Horita, R. E., Watanabe, S., and Sagawa, E.: EXOS D (Akebono) suprathermal mass spectrometer observations of the polar wind, J. Geophys. Res., 98, 11191, doi:10.1029/92JA01971, 1993.

André, M., Li, K., and Eriksson, A. I.: Outflow of low-energy ions and the solar cycle, J. Geophys. Res., 120, 1072-1085, doi:10.1002/2014JA020714, 2015. 
Arzner, K. and Scholer, M.: Kinetic structure of the post plasmoid plasma sheet during magnetotail reconnection, J. Geophys. Res., 106, 3827-3844, doi:10.1029/2000JA000179, 2001.

Axford, W. I.: The polar wind and the terrestrial helium budget, J. Geophys. Res., 73, 6855-6859, doi:10.1029/JA073i021p06855, 1968.

Baker, D. N., Hones, Jr., E. W., Young, D. T., and Birn, J.: The possible role of ionospheric oxygen in the initiation and development of plasma sheet instabilities, Geophys. Res. Lett., 9, 1337-1340, doi:10.1029/GL009i012p01337, 1982.

Banks, P. M. and Holzer, T. E.: The polar wind, J. Geophys. Res., 73, 6846-6854, doi:10.1029/JA073i021p06846, 1968.

Brambles, O. J., Lotko, W., Damiano, P. A., Zhang, B., Wiltberger, M., and Lyon, J.: Effects of causally driven cusp $\mathrm{O}^{+}$outflow on the storm time magnetosphere-ionosphere system using a multifluid global simulation, J. Geophys. Res., 115, A00J04, doi:10.1029/2010JA015469, 2010.

Brambles, O. J., Lotko, W., Zhang, B., Wiltberger, M., Lyon, J., and Strangeway, R. J.: Magnetosphere Sawtooth Oscillations Induced by Ionospheric Outflow, Science, 332, 1183, doi:10.1126/science.1202869, 2011.

Candidi, M., Orsini, S., and Formisano, V.: The properties of ionospheric $\mathrm{O} /+/$ ions as observed in the magnetotail boundary layer and northern plasma lobe, J. Geophys. Res., 87, 9097-9106, doi:10.1029/JA087iA11p09097, 1982.

Candidi, M., Orsini, S., and Ghielmetti, A. G.: Observations of multiple ion beams in the magnetotail Evidence for a double proton population, J. Geophys. Res., 89, 2180-2184, doi:10.1029/JA089iA04p02180, 1984.

Chappell, C. R., Moore, T. E., and Waite Jr., J. H.: The ionosphere as a fully adequate source of plasma for the earth's magnetosphere, J. Geophys. Res., 92, 5896-5910, doi:10.1029/JA092iA06p05896, 1987.

Cladis, J. B. and Francis, W. E.: Distribution in magnetotail of $\mathrm{O}(+)$ ions from cusp/cleft ionosphere - A possible substorm trigger, J. Geophys. Res., 97, 123-130, doi:10.1029/91JA02376, 1992.

Cliver, E. W., Kamide, Y., and Ling, A. G.: Mountains versus valleys: Semiannual variation of geomagnetic activity, J. Geophys. Res., 105, 2413-2424, doi:10.1029/1999JA900439, 2000.

Cully, C. M., Donovan, E. F., Yau, A. W., and Arkos, G. G.: Akebono/Suprathermal Mass Spectrometer observations of low-energy ion outflow: Dependence on magnetic activity and solar wind conditions, J. Geophys. Res., 108, 1093, doi:10.1029/2001JA009200, 2003.

Daglis, I. A. and Axford, W. I.: Fast ionospheric response to enhanced activity in geospace: Ion feeding of the inner magnetotail, J. Geophys. Res., 101, 5047-5066, doi:10.1029/95JA02592, 1996.

Delcourt, D. C., Moore, T. E., and Chappell, C. R.: Contribution of low-energy ionospheric protons to the plasma sheet, J. Geophys. Res., 99, 5681-5689, doi:10.1029/93JA02770, 1994.

Dessler, A. J. and Michel, F. C.: Plasma in the geomagnetic tail, J. Geophys. Res., 71, 1421-1426, doi:10.1029/JZ071i005p01421, 1966.

Dungey, J. W.: Interplanetary Magnetic Field and the Auroral Zones, Phys. Rev. Lett., 6, 47-48, doi:10.1103/PhysRevLett.6.47, 1961.

Ebihara, Y., Yamada, M., Watanabe, S., and Ejiri, M.: Fate of outflowing suprathermal oxygen ions that originate in the polar ionosphere, J. Geophys. Res., 111, A04219, doi:10.1029/2005JA011403, 2006.

Ebihara, Y., Kistler, L. M., and Eliasson, L.: Imaging cold ions in the plasma sheet from the Equator-S satellite, Geophys. Res. Lett., 35, L15103, doi:10.1029/2008GL034357, 2008.

Echer, E., Gonzalez, W. D., and Tsurutani, B. T.: Statistical studies of geomagnetic storms with peak Dst $<-50 \mathrm{nT}$ from 1957 to 2008, J. Atmos. Sol.-Terr. Phy., 73, 1454-1459, doi:10.1016/j.jastp.2011.04.021, 2011.

Emmert, J. T., Richmond, A. D., and Drob, D. P.: A computationally compact representation of Magnetic-Apex and Quasi-Dipole coordinates with smooth base vectors, J. Geophys. Res., 115, A08322, doi:10.1029/2010JA015326, 2010.

Engwall, E., Eriksson, A. I., Cully, C. M., André, M., Puhl-Quinn, P. A., Vaith, H., and Torbert, R.: Survey of cold ionospheric outflows in the magnetotail, Ann. Geophys., 27, 3185-3201, doi:10.5194/angeo-27-3185-2009, 2009.

Escoubet, C. P., Fehringer, M., and Goldstein, M.: Introduction The Cluster mission, Ann. Geophys., 19, 1197-1200, doi:10.5194/angeo-19-1197-2001, 2001.

Förster, M. and Cnossen, I.: Upper atmosphere differences between northern and southern high latitudes: The role of magnetic field asymmetry, J. Geophys. Res., 118, 5951-5966, doi:10.1002/jgra.50554, 2013.

Gary, S. P.: Electromagnetic ion/ion instabilities and their consequences in space plasmas - A review, Space Sci. Rev., 56, 373415, doi:10.1007/BF00196632, 1991.

Glocer, A., Kitamura, N., Toth, G., and Gombosi, T.: Modeling solar zenith angle effects on the polar wind, J. Geophys. Res., 117, A04318, doi:10.1029/2011JA017136, 2012.

Green, J. L. and Waite Jr., J. H.: On the origin of polar ion streams, Geophys. Res. Lett., 12, 149-152, doi:10.1029/GL012i003p00149, 1985.

Haaland, S., Eriksson, A., Engwall, E., Lybekk, B., Nilsson, H., Pedersen, A., Svenes, K., André, M., Förster, M., Li, K., Johnsen, C., and Østgaard, N.: Estimating the capture and loss of cold plasma from ionospheric outflow, J. Geophys. Res., 117, A07311, doi:10.1029/2012JA017679, 2012.

Haaland, S., Eriksson, A., André, M., Maes, L., Baddeley, L., Barakat, A., Chappell, R., Eccles, V., Johnsen, C., Lybekk, B., Li, K., Pedersen, A., Schunk, R., and Welling, D.: Estimation of cold plasma outflow during geomagnetic storms, J. Geophys. Res., 120, 10, doi:10.1002/2015JA021810, 2015.

Huddleston, M. M., Chappell, C. R., Delcourt, D. C., Moore, T. E., Giles, B. L., and Chandler, M. O.: An examination of the process and magnitude of ionospheric plasma supply to the magnetosphere, J. Geophys. Res., 110, A12202, doi:10.1029/2004JA010401, 2005.

Hultqvist, B.: Chapter 1-Introduction, Space Sci. Rev., 88, 1-5, doi:10.1023/A:1005219432375, 1999.

Kistler, L. M., Mouikis, C. G., Cao, X., Frey, H., Klecker, B., Dandouras, I., Korth, A., Marcucci, M. F., Lundin, R., McCarthy, M., Friedel, R., and Lucek, E.: Ion composition and pressure changes in storm time and nonstorm substorms in the vicinity of the near-Earth neutral line, J. Geophys. Res., 111, A11222, doi:10.1029/2006JA011939, 2006.

Kronberg, E. A., Ashour-Abdalla, M., Dandouras, I., Delcourt, D. C., Grigorenko, E. E., Kistler, L. M., Kuzichev, I. V., Liao, J., Maggiolo, R., Malova, H. V., Orlova, K. G., Peroomian, V., Shkl- 
yar, D. R., Shprits, Y. Y., Welling, D. T., and Zelenyi, L. M.: Circulation of Heavy Ions and Their Dynamical Effects in the Magnetosphere: Recent Observations and Models, Space Sci. Rev., 184, 173-235, doi:10.1007/s11214-014-0104-0, 2014.

Li, K., Haaland, S., Eriksson, A., André, M., Engwall, E., Wei, Y., Kronberg, E. A., Fränz, M., Daly, P. W., Zhao, H., and Ren, Q. Y.: On the ionospheric source region of cold ion outflow, Geophys. Res. Lett., 39, L18102, doi:10.1029/2012GL053297, 2012.

Li, K., Haaland, S., Eriksson, A., André, M., Engwall, E., Wei, Y., Kronberg, E. A., Fränz, M., Daly, P. W., Zhao, H., and Ren, Q. Y.: Transport of cold ions from the polar ionosphere to the plasma sheet, J. Geophys. Res., 118, 5467-5477, doi:10.1002/jgra.50518, 2013.

Liao, J., Cai, X., Kistler, L. M., Clauer, C. R., Mouikis, C. G., Klecker, B., and Dandouras, I.: The relationship between sawtooth events and $\mathrm{O}^{+}$in the plasma sheet, J. Geophys. Res., 119, 1572-1586, doi:10.1002/2013JA019084, 2014.

Lockwood, M., Waite Jr., J. H., Moore, T. E., Chappell, C. R., and Chandler, M. O.: The cleft ion fountain, J. Geophys. Res., 90, 9736-9748, doi:10.1029/JA090iA10p09736, 1985.

Lotko, W.: The magnetosphere ionosphere system from the perspective of plasma circulation: A tutorial, J. Atmos. Sol.-Terr. Phy., 69, 191-211, doi:10.1016/j.jastp.2006.08.011, 2007.

Maes, L., Maggiolo, R., De Keyser, J., Dandouras, I., Fear, R. C., Fontaine, D., and Haaland, S.: Solar illumination control of ionospheric outflow above polar cap arcs, Geophys. Res. Lett., 42, 1304-1311, doi:10.1002/2014GL062972, 2015.

Maggiolo, R. and Kistler, L. M.: Spatial variation in the plasma sheet composition: Dependence on geomagnetic and solar activity, J. Geophys. Res., 119, 2836-2857, doi:10.1002/2013JA019517, 2014.

Moore, T. E. and Khazanov, G. V.: Mechanisms of ionospheric mass escape, J. Geophys. Res., 115, A00J13, doi:10.1029/2009JA014905, 2010.

Nagai, T., Waite Jr., J. H., Green, J. L., Chappell, C. R., Olsen, R. C., and Comfort, R. H.: First measurements of supersonic polar wind in the polar magnetosphere, Geophys. Res. Lett., 11, 669-672, doi:10.1029/GL011i007p00669, 1984.

Nilsson, H., Barghouthi, I. A., Slapak, R., Eriksson, A. I., and André, M.: Hot and cold ion outflow: Spatial distribution of ion heating, J. Geophys. Res., 117, A11201, doi:10.1029/2012JA017974, 2012.

Ouellette, J. E., Brambles, O. J., Lyon, J. G., Lotko, W., and Rogers, B. N.: Properties of outflow-driven sawtooth substorms, J. Geophys. Res., 118, 3223-3232, doi:10.1002/jgra.50309, 2013.

Peterson, W. K.: Ionospheric Influence on Substorm Development, Proceedings of the Sixth International Conference on Substorms, University of Washington, p. 143, 2002.

Peterson, W. K., Sharp, R. D., Shelley, E. G., Johnson, R. G., and Balsiger, H.: Energetic ion composition of the plasma sheet, J. Geophys. Res., 86, 761-767, doi:10.1029/JA086iA02p00761, 1981.

Russell, C. T. and McPherron, R. L.: Semiannual variation of geomagnetic activity, J. Geophys. Res., 78, 92, doi:10.1029/JA078i001p00092, 1973.

Sabine, E.: On Periodical Laws Discoverable in the Mean Effects of the Larger Magnetic Disturbances. No. III, Philosophical Transactions of the Royal Society of London Series I, 146, 357-374, 1856.
Seki, K., Hirahara, M., Terasawa, T., Mukai, T., Saito, Y., Machida, S., Yamamoto, T., and Kokubun, S.: Statistical properties and possible supply mechanisms of tailward cold $\mathrm{O}^{+}$beams in the lobe/mantle regions, J. Geophys. Res., 103, 4477-4490, doi:10.1029/97JA02137, 1998.

Seki, K., Elphic, R. C., Hirahara, M., Terasawa, T., and Mukai, T.: On Atmospheric Loss of Oxygen Ions from Earth Through Magnetospheric Processes, Science, 291, 1939-1941, doi:10.1126/science.1058913, 2001.

Seki, K., Hirahara, M., Hoshino, M., Terasawa, T., Elphic, R. C., Saito, Y., Mukai, T., Hayakawa, H., Kojima, H., and Matsumoto, H.: Cold ions in the hot plasma sheet of Earth's magnetotail, Nature, 422, 589-592, 2003.

Sharp, R. D., Carr, D. L., Peterson, W. K., and Shelley, E. G.: Ion streams in the magnetotail, J. Geophys. Res., 86, 4639-4648, doi:10.1029/JA086iA06p04639, 1981.

Shay, M. A. and Swisdak, M.: Three-Species Collisionless Reconnection: Effect of $\mathrm{O}^{+}$on Magnetotail Reconnection, Phys. Rev. Lett., 93, 175001, doi:10.1103/PhysRevLett.93.175001, 2004.

Slapak, R., Nilsson, H., Westerberg, L. G., and Larsson, R.: $\mathrm{O}^{+}$ transport in the dayside magnetosheath and its dependence on the IMF direction, Ann. Geophys., 33, 301-307, doi:10.5194/angeo33-301-2015, 2015.

Slavin, J. A., Baker, D. N., Fairfield, D. H., Craven, J. D., Frank, L. A., Elphic, R. C., Galvin, A. B., Hughes, W. J., Manka, R. H., and Smith, E. J.: CDAW 8 observations of plasmoid signatures in the geomagnetic tail - An assessment, J. Geophys. Res., 94, 15153-15175, doi:10.1029/JA094iA11p15153, 1989.

Slavin, J. A., Hesse, M., Owen, C. J., Taguchi, S., Fairfield, D. H., Lepping, R. P., Kokubun, S., Mukai, T., Lui, A. T. Y., Anderson, R. R., Matsumoto, H., and Sutcliffe, P. R.: Dual spacecraft observations of lobe magnetic field perturbations before, during and after plasmoid release, Geophys. Res. Lett., 26, 2897-2900, doi:10.1029/1999GL003606, 1999.

Su, Y.-J., Horwitz, J. L., Moore, T. E., Giles, B. L., Chandler, M. O., Craven, P. D., Hirahara, M., and Pollock, C. J.: Polar wind survey with the Thermal Ion Dynamics Experiment/Plasma Source Instrument suite aboard POLAR, J. Geophys. Res., 103, 2930529338, doi:10.1029/98JA02662, 1998a.

Su, Y.-J., Horwitz, J. L., Wilson, G. R., Richards, P. G., Brown, D. G., and Ho, C. W.: Self-consistent simulation of the photoelectron-driven polar wind from $120 \mathrm{~km}$ to $9 \mathrm{R}_{E}$ altitude, J. Geophys. Res., 103, 2279-2296, doi:10.1029/97JA03085, 1998b.

Tam, S. W. Y., Chang, T., and Pierrard, V.: Kinetic modeling of the polar wind, J. Atmos. Sol.-Terr. Phys., 69, 1984-2027, doi:10.1016/j.jastp.2007.08.006, 2007.

Thébault, E., Finlay, C. C., Beggan, C. D., Alken, P., Aubert, J., Barrois, O., Bertrand, F., Bondar, T., Boness, A., Brocco, L., Canet, E., Chambodut, A., Chulliat, A., Coïsson, P., Civet, F., Du, A., Fournier, A., Fratter, I., Gillet, N., Hamilton, B., Hamoudi, M., Hulot, G., Jager, T., Korte, M., Kuang, W., Lalanne, X., Langlais, B., Léger, J.-M., Lesur, V., Lowes, F. J., Macmillan, S., Mandea, M., Manoj, C., Maus, S., Olsen, N., Petrov, V., Ridley, V., Rother, M., Sabaka, T. J., Saturnino, D., Schachtschneider, R., Sirol, O., Tangborn, A., Thomson, A., Tøffner-Clausen, L., Vigneron, P., Wardinski, I., and Zvereva, T.: International Geomagnetic Reference Field: the 12th generation, Earth Planet. Space, 67, 79, doi:10.1186/s40623-015-0228-9, 2015. 
Toledo-Redondo, S., Vaivads, A., André, M., and Khotyaintsev, Y. V.: Modification of the Hall physics in magnetic reconnection due to cold ions at the Earth's magnetopause, Geophys. Res. Lett., 42, 6146-6154, doi:10.1002/2015GL065129, 2015.

Tsurutani, B. T. and Gonzalez, W. D.: The future of geomagnetic storm predictions: implications from recent solar and interplanetary observations., J. Atmos. Terr. Phys., 57, 1369-1384, 1995.

Tsyganenko, N. A.: A magnetospheric magnetic field model with a warped tail current sheet, Planet. Space Sci., 37, 5-20, doi:10.1016/0032-0633(89)90066-4, 1989.

Waite Jr., J. H., Chappell, C. R., Nagai, T., Johnson, J. F. E., Burch, J. L., Killeen, T. L., Hays, P. B., Carignan, G. R., Peterson, W. K., and Shelley, E. G.: Escape of suprathermal $\mathrm{O}(+)$ ions in the polar cap, J. Geophys. Res., 90, 1619-1630, doi:10.1029/JA090iA02p01619, 1985.
Yau, A. W. and André, M.: Sources of Ion Outflow in the High Latitude Ionosphere, Space Sci. Rev., 80, 1-25, doi:10.1023/A:1004947203046, 1997.

Yau, A. W., Peterson, W. K., and Shelley, E. G.: Quantitative parametrization of energetic ionospheric ion outflow, Washington DC American Geophysical Union, Geoph. Monog. Series, 44, 211-217, doi:10.1029/GM044p0211, 1988.

Yu, Y. and Ridley, A. J.: Exploring the influence of ionospheric $\mathrm{O}^{+}$outflow on magnetospheric dynamics: dependence on the source location, J. Geophys. Res., 118, 1711-1722, doi:10.1029/2012JA018411, 2013.

Zheng, Y., Moore, T. E., Mozer, F. S., Russell, C. T., and Strangeway, R. J.: Polar study of ionospheric ion outflow versus energy input, J. Geophys. Res., 110, A07210, doi:10.1029/2004JA010995, 2005. 